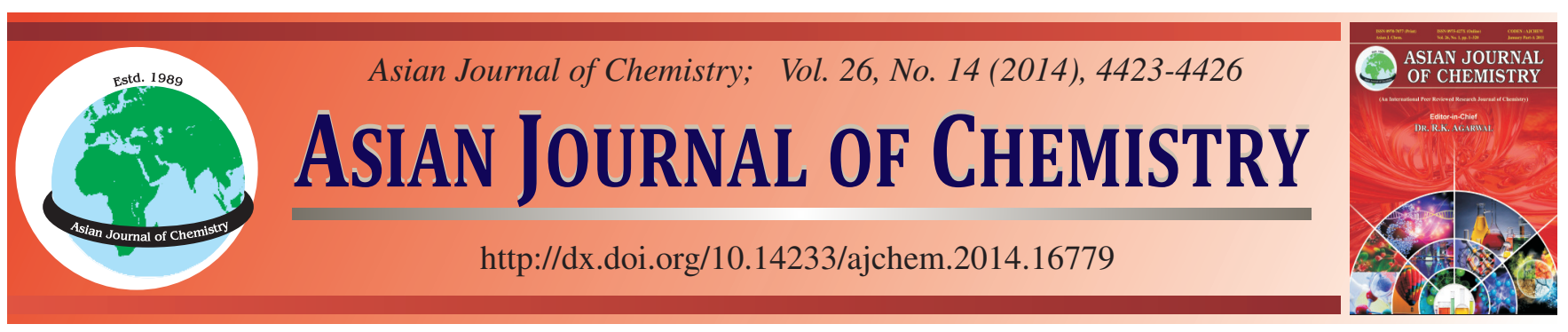

\title{
Preparation of $\mathrm{SrBi}_{2} \mathrm{O}_{4} / \mathrm{Ti}$ Anode and Its Photocatalytic and Photoelectrochemical Oxidation Performance
}

\author{
Guoting Li, ZhaO Ye and LingFeng Zhu*
}

Institute of Environmental and Municipal Engineering, North China University of Water Resources and Electric Power, Zhengzhou 450011, P.R. China

*Corresponding author: Tel/Fax: +86 371 65790239; E-mail: zhulingfengzy@ncwu.edu.cn

Received: 28 November 2013;

Accepted: 20 February 2014;

Published online: 5 July 2014;

AJC-15488

DSA anode $\mathrm{SrBi}_{2} \mathrm{O}_{4} / \mathrm{Ti}$ is prepared and used for photocatalytic and photoelectrochemical oxdiation of azo dye Orange $\mathrm{II}_{\text {. }} \mathrm{SrBi}_{2} \mathrm{O}_{4}$ is tentatively immobilized onto $\mathrm{H}_{2} \mathrm{C}_{2} \mathrm{O}_{4}$ treated $\mathrm{Ti}$ substrate by dip-coating of $\mathrm{SrBi}_{2} \mathrm{O}_{4}$ precursor solution. Subsequent calicination of the immobilized Ti substrate at $700{ }^{\circ} \mathrm{C}$ for $2 \mathrm{~h}$ could produce $\mathrm{SrBi}_{2} \mathrm{O}_{4} / \mathrm{Ti}$ anode. The surface pore structure of $\mathrm{H}_{2} \mathrm{C}_{2} \mathrm{O}_{4}$ treated Ti substrate facilitates the combination between $\mathrm{SrBi}_{2} \mathrm{O}_{4}$ crystals and Ti substrate by SEM analysis. The average diameter of $\mathrm{SrBi}_{2} \mathrm{O}_{4}$ crytals is within $5 \mu \mathrm{m}$ and they are compactly combined with each other. The component and crystal structure of $\mathrm{SrBi}_{2} \mathrm{O}_{4}$ are also confirmed by EDX and XRD analysis. Under the irradiation from Xenon lamp (with UV-cutoff filter), tungsten lamp and ultraviolet lamp, the Orange II decolorization efficiency by photoelectrochemical oxidation is significantly higher than those by photocatalytic oxidation and electrochemical oxidation alone. Meanwhile, the synergetic factor $\mathrm{f}$ under tungsten lamp irradiation achieves $239.5 \%$, which is more significant than under visible and ultraviolet irradiation. Both the wavelength of light source and the proportion between visible light and ultraviolet are proved to be fundamental for the photoelectrochemical process.

Keywords: $\mathrm{SrBi}_{2} \mathrm{O}_{4}$, Anode, Photocatalytic oxidation, Electrochemical oxidation, Photoelectrochemical oxidation.

\section{INTRODUCTION}

Advanced oxidation processes (AOPs) are all characterized by the production and utilization of $\mathrm{HO}^{\circ}$ radicals $(2.72$ $\mathrm{V} / \mathrm{NHE}$ ), which are the most reactive radicals in aqueous solution ${ }^{1}$. Pathogenic organisms could be efficiently killed by the oxidizing species produced by $\mathrm{AOPs}^{2,3}$. A number of organic pollutants, particularly toxic and refractory pollutants, can be degraded effectively and even mineralized to carbon oxide, water and inorganics if the reaction time was prolonged ${ }^{4-7}$. Due to the wide application, AOPs are currently receiving the ever-increasing concern around the world.

Among advanced oxidation processes, photocatalytic oxidation and electrochemical oxidation processes are especially interesting as they can be integrated to be photoelectrochemical oxidation process. In terms of photocatalytic oxidation, the recombination of charge carriers on semiconductors could result in low quantum efficiency and poor degradation performance ${ }^{8}$. For electrochemical oxidation, partial degradation of aromatics could lead to the accumulation of intermediates with higher toxicity than their parent molecules, which is attributed to the insufficient generation of oxidizing species ${ }^{9-11}$. By application of an external electric field on an anode with photocatalytic activity, charge carriers can be effectively separated in photocatalytic oxidation process. Meanwhile, the enhanced photocatalytic oxidation efficiency could help to produce more oxidizing species for organics degradation. A synergetic effect was always observed in photoelectrochemical oxidation process $^{6,12}$. Accordingly, photoelectrochemical oxidation is a promising technology for organics degradation in water and wastewater purification.

For photocatalytic oxidation and electrochemical oxidation processes, catalytic materials play the key role as the reaction efficiency is highly dependent on the type of catalytic material. Therefore, the selection of anode material for photoelectrochemical oxidation is considered to be vital for the total performance. On the other hand, the light source is also fundamental for the degradation efficiency. Ultraviolet irradiation consists of only about $5 \%$ of total solar energy, while visible light accounts for as much as $45 \%$. The utilization of both ultraviolet and visible light in photoelectro-chemical oxidation process seems to be more important from a practical point of view.

In this research, $\mathrm{SrBi}_{2} \mathrm{O}_{4}$, a visible light active catalyst ${ }^{13,14}$, is tentatively immobilized onto a $\mathrm{H}_{2} \mathrm{C}_{2} \mathrm{O}_{4}$ treated Ti substrate. The prepared anode $\mathrm{SrBi}_{2} \mathrm{O}_{4} / \mathrm{Ti}$ is used in the photocatalytic oxidation, electrochemical oxidation and photoelectrochemical oxidation of an azo dye Orange II. Xenon lamp (with UV- 
cutoff filter), tungsten lamp and ultraviolet lamp are employed to proved visible light, simulated solar light and ultraviolet irradiation to explore the degradation performance.

\section{EXPERIMENTAL}

Orange II was purchased from the Beijing Chemical Reagents Company and used without further purification. Other chemicals used were of analytical-reagent grade. The titanium substrate $(40 \times 50 \mathrm{~mm})$ was provided by the Beijing Titanium Industrial and Trade Company. Visible light irradiation was provided by a $150 \mathrm{~W}$ Xenon lamp (Zhuolihanguang Instrument Corporation, Ltd., Beijing, China) with a UV cut-off filter to remove the light with wavelength shorter than $400 \mathrm{~nm}$. A $15 \mathrm{~W}$ UV lamp (Aosilan Instrument Corporation, Ltd., Wenzhou, China) with a maximum emission at $254 \mathrm{~nm}$ was used to provide the ultraviolet irradiation. A commercially available $100 \mathrm{~W}$ tungsten lamp was employed to simulate solar light irradiation.

Preparation of $\mathrm{SrBi}_{2} \mathrm{O}_{4} / \mathrm{Ti}$ anode: Pretreatment of the titanium substrate surface $(40 \times 50 \mathrm{~mm})$ was carried out following the procedures suggested by Feng and Johnson ${ }^{15}$. The mesh was degreased with $40 \% \mathrm{NaOH}$ solution. Then it was immersed in a boiling aqueous solution of $\mathrm{H}_{2} \mathrm{C}_{2} \mathrm{O}_{4}(15 \%)$ until $\mathrm{TiO}_{2}$ dissolved, producing grey titanium substrate.

The precursor solution was prepared by mixing $\mathrm{Bi}\left(\mathrm{NO}_{3}\right)_{3} \cdot 5 \mathrm{H}_{2} \mathrm{O}, \mathrm{Sr}\left(\mathrm{NO}_{3}\right)_{2}, \mathrm{HNO}_{3}$, citric acid and glycol with a desired proportion. Initially, certain amount of $\mathrm{Bi}\left(\mathrm{NO}_{3}\right)_{3} \cdot 5 \mathrm{H}_{2} \mathrm{O}$ was added into dilute $\mathrm{HNO}_{3}$ solution until $\mathrm{Bi}\left(\mathrm{NO}_{3}\right)_{3} \cdot 5 \mathrm{H}_{2} \mathrm{O}$ was completely dissolved. Subsequently, $\mathrm{Sr}\left(\mathrm{NO}_{3}\right)_{2}$, glycol and citric acid were sequentially added in the above aqueous solution, in which the molar ratio between $\mathrm{Sr}\left(\mathrm{NO}_{3}\right)_{2}$ and $\mathrm{Bi}\left(\mathrm{NO}_{3}\right)_{3}$ was maintained at 1:2. The mixture was kept stirring for $2-3 \mathrm{~h}$ and a transparent precursor solution was obtained.

The $\mathrm{H}_{2} \mathrm{C}_{2} \mathrm{O}_{4}$ treated titanium substrate was dipped in the precursor solution. After being taken out of the mixture, the titanium substrate was dried in an oven at $120{ }^{\circ} \mathrm{C}$ for $0.5 \mathrm{~h}$. The thickness of the film was controlled by the repeated times of dip coating procedure. Then the titanium substrate was heated at $700{ }^{\circ} \mathrm{C}$ in a muffle furnace for $2 \mathrm{~h}$ and $\mathrm{SrBi}_{2} \mathrm{O}_{4} / \mathrm{Ti}$ anode was prepared. $\mathrm{H}_{2} \mathrm{C}_{2} \mathrm{O}_{4}$ treated $\mathrm{Ti}$ substrate was also calcined in the muffle furnace with same procedures.

Characterization: The morphologies of titanium substrate and $\mathrm{SrBi}_{2} \mathrm{O}_{4} / \mathrm{Ti}$ anode were recorded on a Philips Quanta2000 scanning microscope coupled with an energy dispersive $\mathrm{X}$-ray (EDX) spectrometer. The X-ray diffraction (XRD) patterns of $\mathrm{SrBi}_{2} \mathrm{O}_{4} / \mathrm{Ti}$ and the thermally treated $\mathrm{Ti}$ substrate were recorded on a Rigaku D/MAX-3B X-diffractometer.

Degradation of orange II by photocatalytic oxidation, electrochemical oxidation and photoelectrochemical oxidation: These reactions were carried out in a semi-cylindrical quartz reactor. Titanium wire was used as cathode and the prepared $\mathrm{SrBi}_{2} \mathrm{O}_{4} / \mathrm{Ti}$ anode was employed. The available volume of the reactor was 150 and $125 \mathrm{~mL}$ Orange II $(20 \mathrm{mg} / \mathrm{L})$ solution was added. Irradiations from $150 \mathrm{~W}$ Xenon lamp (with UV-cutoff filter), $100 \mathrm{~W}$ tungsten lamp and $15 \mathrm{~W}$ UV lamp was applied on the prepared $\mathrm{SrBi}_{2} \mathrm{O}_{4} / \mathrm{Ti}$ anode. The lamps were situated parallel to the anode tested at a distance of $30 \mathrm{~mm}$ from the quartz reactor.

Analyses: An UVmini 1240 UV-visible spectrophotometer (Shimadzu, Japan) was employed to measure the concentration of Orange II samples at $484 \mathrm{~nm}$, which corresponded to the maximum absorption of the dye.

\section{RESULTS AND DISCUSSION}

Surface morphologies of raw Ti substrate, $\mathrm{H}_{2} \mathrm{C}_{2} \mathrm{O}_{4}$ treated Ti substrate $\mathrm{SrBi}_{2} \mathrm{O}_{4} / \mathrm{Ti}$ anode: $\mathrm{SEM}$ images of raw Ti substrate, $\mathrm{H}_{2} \mathrm{C}_{2} \mathrm{O}_{4}$ treated Ti substrate and $\mathrm{SrBi}_{2} \mathrm{O}_{4} / \mathrm{Ti}$ anode are presented in Fig.1. Apparently, compared with the smooth raw Ti substrate in Fig. 1 a and b, many pores and honey-comb
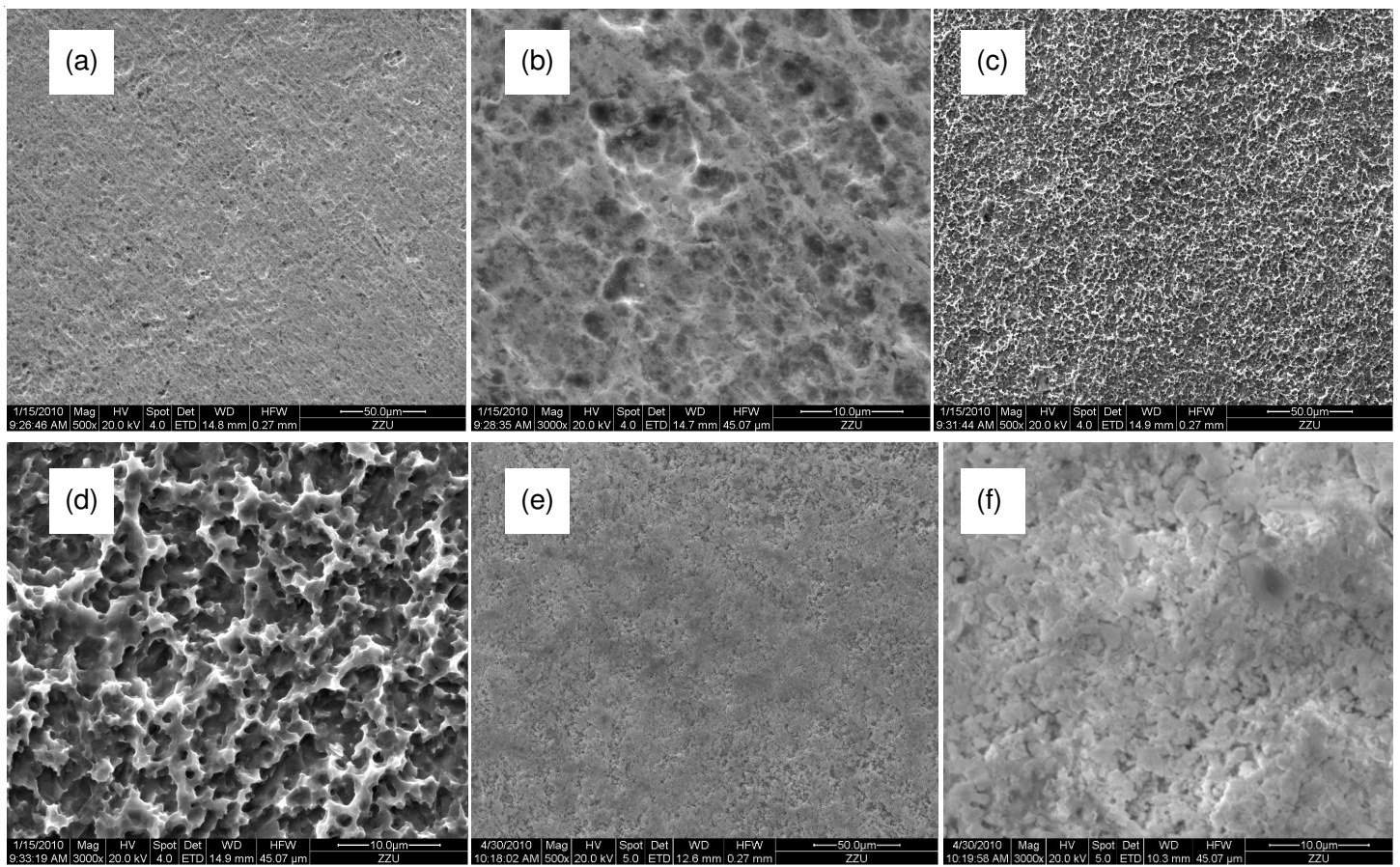

(e)

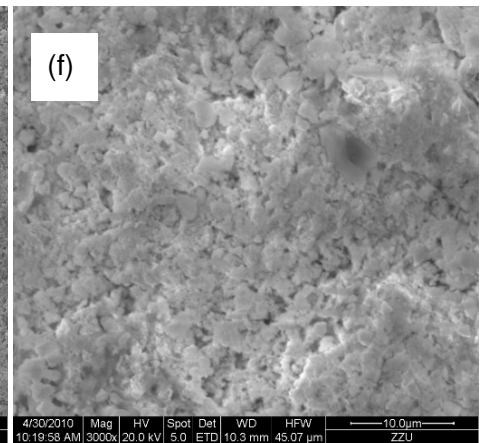

Fig. 1. SEM micrographs of raw Ti substrate (a,b), $\mathrm{H}_{2} \mathrm{C}_{2} \mathrm{O}_{4}$ treated Ti substrate (c,d), and $\mathrm{SrBi}_{2} \mathrm{O}_{4} / \mathrm{Ti}$ anode (e,f). (a), (c) and (e) are magnified 500 times while (b), (d) and (f) are magnified 3000 times 
structures are generated on the Ti substrate after chemical etching in boiling $\mathrm{H}_{2} \mathrm{C}_{2} \mathrm{O}_{4}$ solution. As illustrated in Fig.1 c and $\mathrm{d}$, the average diameter of these pores is within $10 \mu \mathrm{m}$ and they are compactly distributed on the anode surface, which is consistent with previous study ${ }^{16}$. Meanwhile, the rough surface of the $\mathrm{H}_{2} \mathrm{C}_{2} \mathrm{O}_{4}$ treated Ti substrate is expected to facilitate the immobilization of $\mathrm{SrBi}_{2} \mathrm{O}_{4}$ crystals. As a comparison, in Fig. 1e and $\mathrm{f}, \mathrm{SrBi}_{2} \mathrm{O}_{4}$ crytals has been immobilized onto the Ti substrate. The pore structures on the $\mathrm{H}_{2} \mathrm{C}_{2} \mathrm{O}_{4}$ treated $\mathrm{Ti}$ substrate are occupied by the $\mathrm{SrBi}_{2} \mathrm{O}_{4}$ crytals, indicating a good combination between $\mathrm{SrBi}_{2} \mathrm{O}_{4}$ crytals and Ti substrate. The $\mathrm{SrBi}_{2} \mathrm{O}_{4}$ crytals are observed to be evenly distributed on the anode surface. The average diameter of these crytals is within $5 \mu \mathrm{m}$ and they are compactly combined with each other as well.

The EDX microanalysis of $\mathrm{SrBi}_{2} \mathrm{O}_{4} / \mathrm{Ti}$ electrode was also conducted to further confirm the existence of $\mathrm{SrBi}_{2} \mathrm{O}_{4}$ coating, as presented in Fig. 2. The molar ratios of $\mathrm{Sr}$ and $\mathrm{Bi}$ are 9.2 and $12.5 \%$, respectively. The main elements for the $\mathrm{SrBi}_{2} \mathrm{O}_{4} /$ $\mathrm{Ti}$ are $\mathrm{Sr}, \mathrm{Bi}, \mathrm{Ti}$ and $\mathrm{O}$. The coexistence of $\mathrm{TiO}_{2}$ indicates that thickness of the $\mathrm{SrBi}_{2} \mathrm{O}_{4}$ coating is not thick enough to cover the $\mathrm{Ti}$ substrate totally. Consequently, $\mathrm{TiO}_{2}$ can be formed concurrently after calcination at $700{ }^{\circ} \mathrm{C}$ in a muffle furnace.

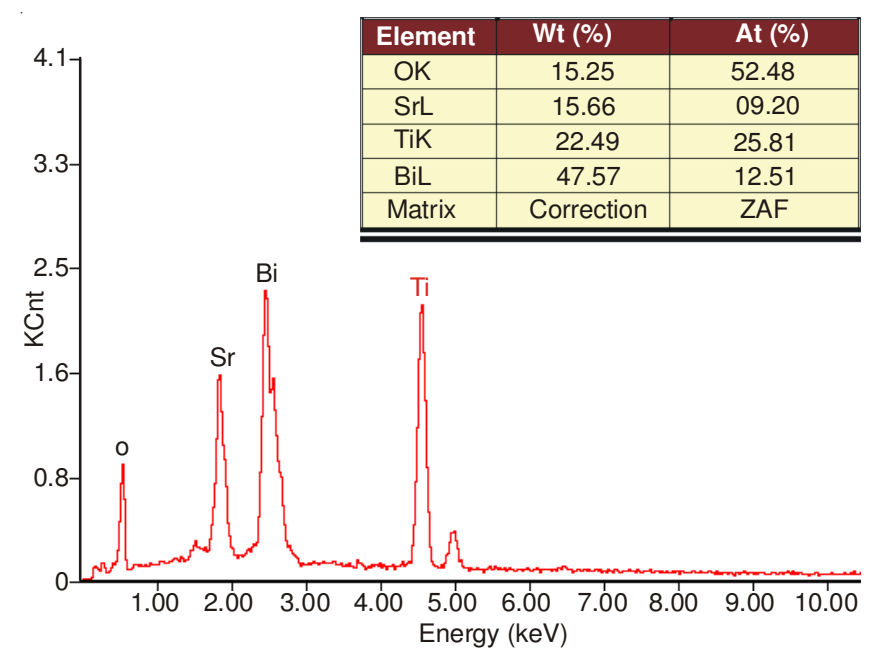

Fig. 2. EDX graph of $\mathrm{SrBi}_{2} \mathrm{O}_{4} / \mathrm{Ti}$ anode

XRD of $\mathrm{SrBi}_{2} \mathrm{O}_{4} / \mathrm{Ti}$ anode: XRD patterns of $\mathrm{SrBi}_{2} \mathrm{O}_{4} / \mathrm{Ti}$ anode and thermally treated $\mathrm{Ti}$ substrate are illustrated in Fig. 3. Obviously, $\mathrm{SrBi}_{2} \mathrm{O}_{4} / \mathrm{Ti}$ anode shares all the diffraction peaks which are attributed to the thermally treated Ti substrate.
It indicates that the anode surface is not completely covered by $\mathrm{SrBi}_{2} \mathrm{O}_{4}$, which is consistent with the aforementioned EDX results. On the other hand, the other peaks except that of the thermally treated $\mathrm{Ti}$ substrate $\mathrm{c}$ are attributed to $\mathrm{SrBi}_{2} \mathrm{O}_{4}$.

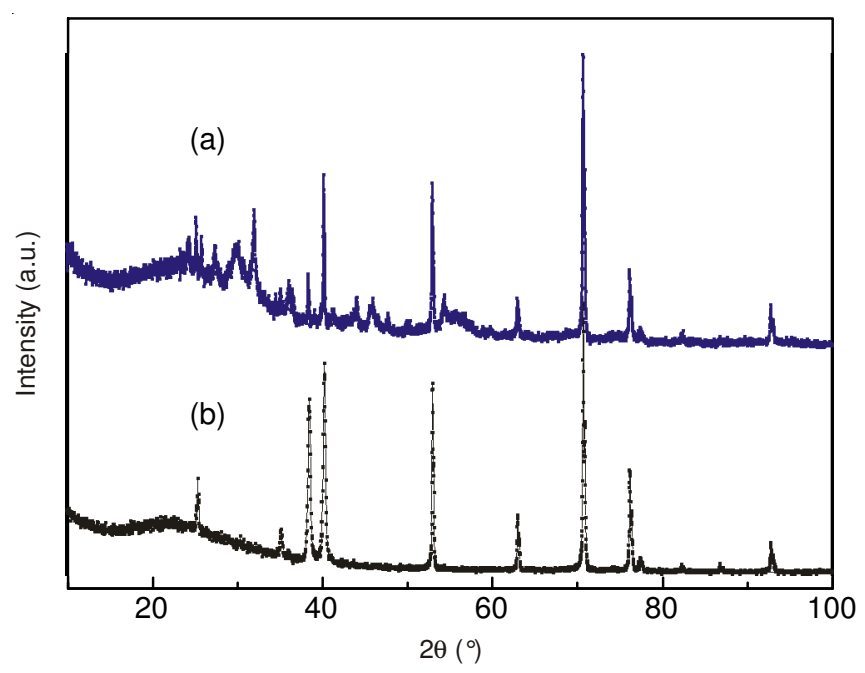

Fig. 3. XRD patterns of $\mathrm{SrBi}_{2} \mathrm{O}_{4} / \mathrm{Ti}$ anode (a) and thermally treated $\mathrm{Ti}$ sunstrate (b)

Photocatalytic and photoelectrochemical performance under different lamp source irradiation: Three processes including photocatalytic oxidation (PO), electrochemical oxidation (EO) and photoelectrochemical oxidation process (PE) are employed to explore the performance of the prepared $\mathrm{SrBi}_{2} \mathrm{O}_{4} / \mathrm{Ti}$ anode. Irradiation from Xenon lamp (with UVcutoff filter), tungsten lamp and ultraviolet lamp are compared during the degradation, which is presented in Fig. 4. The current under $1.5 \mathrm{~V}$ potential was not detected using a amperometer as no electrolyte was introduced in the Orange II solution. As a result, the effect of electrochemical oxidation is apparently insignificant as the removal efficiency only achieves $1.3 \%$. Regarding the photocatalytic oxidation process, the removal efficiencies under visible light (Xenon lamp with UVcutoff filter), tungsten lamp and ultraviolet irradiation reaches $1.0,1.5$ and $28.6 \%$, respectively. This implies that the irradiation wavelength plays the predominant role for photocatalytic oxidation of Orange II using the prepared anode. In addition, the removal efficiencies of photoelectrochemical process are the highest among the three processes. Particularly under
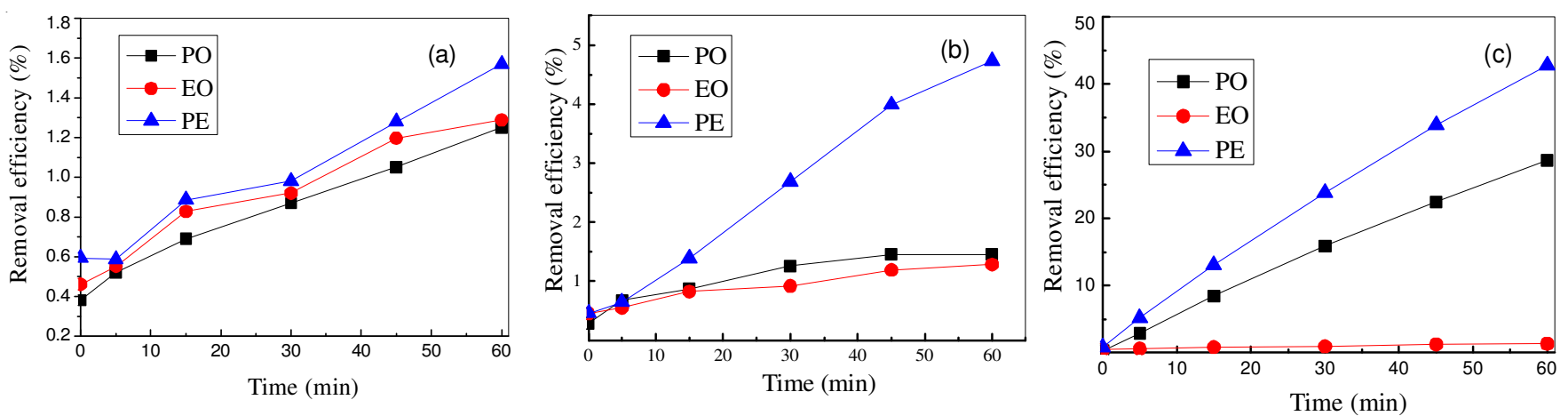

Fig. 4. Decolorization of Orange II by photocatalytic oxidation (PO), electrochemical oxidation (EO) and photoelectrochemical process (PE) under Xenon lamp (with UV-cutoff filter) (a), tungsten lamp (b) and ultraviolet irradiation (c) 
tungsten lamp irradiation, the efficiency of photoelectrochemical process is obviously higher than other two processes.

Synergetic effect during photocatalytic and photoelectrochemical degradation process: For photocatalytic oxidation, electrochemical oxidation and photoelectro-chemical oxidation processes, the degradation processes can be well followed by pseudo-first-order reaction model. The correlation between $\ln \left(\mathrm{C}_{0} / \mathrm{C}\right)$ and reaction time is linear. The kinetic expression can be presented as follows:

$$
\ln \left(\mathrm{C}_{0} / \mathrm{C}\right)=\mathrm{k}_{\mathrm{app}} \mathrm{t}
$$

where $\mathrm{C}_{0}$ is the initial Orange II concentration, $\mathrm{C}$ is the Orange II concentration at instant $\mathrm{t}, \mathrm{k}_{\mathrm{app}}\left(\mathrm{min}^{-1}\right)$ is the apparent rate constant of pseudo-first-order reaction and ' $t$ ' is the time of reaction.

Due to the especially low reaction rate under visible light irradiation, the $\mathrm{k}_{\text {app }}$ for the three processes are very close and insignificant. Herein, only the $\mathrm{k}_{\text {app }}$ values under tungsten lamp and ultraviolet irradiation are presented in Table-1. The $\mathrm{k}_{\text {app }}$ in photoelectrochemical oxidation process under tungsten lamp and ultraviolet irradiation achieves $7.73 \times 10^{-4}$ and $0.0092 \mathrm{~min}^{-1}$, respectively. It is obvious that ultraviolet irradiation is more powerful than tungsten lamp and ultraviolet irradiation in both photocatalytic oxidation and photoelectrochemical oxidation processes.

\begin{tabular}{ccccc}
\multicolumn{5}{c}{ TABLE-1 } \\
\multicolumn{5}{c}{ REACTION RATE CONSTANTS $\left(k_{\text {app }}\right)$ UNDER } \\
TUNGSTEN LAMP AND ULTRAVIOLET IRRADIATION \\
\hline Irradiation & & PO & EO & PE \\
\hline Tungsten & $k_{\text {app }}\left(\mathrm{min}^{-1}\right)$ & $1.46 \times 10^{-4}$ & $8.12 \times 10^{-5}$ & $7.73 \times 10^{-4}$ \\
lamp & $\mathrm{R}^{2}$ & 0.960 & 0.994 & 0.997 \\
Ultraviolet & $k_{\text {app }}\left(\mathrm{min}^{-1}\right)$ & 0.00559 & $8.12 \times 10^{-5}$ & 0.0092 \\
lamp & $\mathrm{R}^{2}$ & 0.999 & 0.994 & 0.999 \\
\hline
\end{tabular}

As we know, photocatalytic oxidation could be enhanced significantly by the application of an external electric field, which is called photoelectrochemical process ${ }^{17}$. A synergetic effect may be observed for the integrated process. In order to clearly indicate the synergetic effect, synergetic factor (f) is introduced as following ${ }^{18}$ :

$$
\mathrm{f}=\left[\mathrm{k}_{\mathrm{PE}} /\left(\mathrm{k}_{\mathrm{PO}}+\mathrm{k}_{\mathrm{EO}}\right)-1\right] \times 100 \%
$$

where $\mathrm{k}_{\mathrm{PE}}$ is the $\mathrm{k}_{\text {app }}$ for photoeletrochemical oxidation process, $\mathrm{k}_{\mathrm{PO}}$ is $\mathrm{k}_{\mathrm{app}}$ for photocatalytic oxidation process and $\mathrm{k}_{\mathrm{EO}}$ is $\mathrm{k}_{\mathrm{app}}$ for electrochemical oxidation process.

The resulted synergetic factors showed in Table-2. The higher the ' $\mathrm{f}$ ' value is, the more significant the synergetic effect. It can be observed that the ' $\mathrm{f}$ ' value under tungsten lamp irradiation achieves $239.5 \%$, which is much higher than that under ultraviolet irradiation. Compared with the overall ultraviolet irradiation, only a small part of ultraviolet irradiation can be detected in the tungsten lamp irradiation. Even though, the synergetic effect is still considerable for tungsten lamp irradiation. The above indicates that both the wavelength of the light source and the proportion between visible light and ultraviolet are fundamental for the photoelectrochemical process.

\begin{tabular}{ccc}
\multicolumn{3}{c}{ TABLE-2 } \\
\multicolumn{3}{c}{ VALUE OF $F$ UNDER TUNGSTEN AND } \\
ULTRAVIOLET LAMP IRRADIATION \\
\hline Irradiation & Tungsten lamp & Ultraviolet lamp \\
\hline $\mathrm{f}$ & $239.5 \%$ & $62.2 \%$ \\
\hline
\end{tabular}

\section{Conclusion}

$\mathrm{SrBi}_{2} \mathrm{O}_{4} / \mathrm{Ti}$ anode is prepared by dip-coating of $\mathrm{SrBi}_{2} \mathrm{O}_{4}$ precursor solution onto $\mathrm{H}_{2} \mathrm{C}_{2} \mathrm{O}_{4}$ treated Ti substrate and subsequent calcination procedure. The surface compact $\mathrm{SrBi}_{2} \mathrm{O}_{4}$ crystals have a good combination with Ti substrate. The component and crystal structure of $\mathrm{SrBi}_{2} \mathrm{O}_{4}$ are also confirmed by EDX and XRD analysis. Under the irradiation from Xenon lamp (with UV-cutoff filter), tungsten lamp and ultraviolet lamp, the Orange II decolorization efficiency by photoelectrochemical oxidation is significantly higher than those by photocatalytic oxidation and electrochemical oxidation alone. Meanwhile, the synergetic effect under tungsten lamp irradiation is the most significant. Both the wavelength of the light source and the proportion between visible light and ultraviolet are proved to be fundamental for the photoelectrochemical process.

\section{ACKNOWLEDGEMENTS}

The authors would like to thank the financial support of the starting fund for talents of North China University of Water Resources and Electric Power and the National Science Foundation of China (Grant No. 50708037).

\section{REFERENCES}

1. R. Andreozzi, V. Caprio, A. Insola and R. Marotta, Catal. Today, 53, 51 (1999).

2 S. Malato, P. Fernández-Ibáñez, M.I. Maldonado, J. Blanco and W. Gernjak, Catal. Today, 147, 1 (2009).

3. A. Yasar, N. Ahmad, H. Latif and A.A.A. Khan, Ozone Sci. Eng., 29, 485 (2007).

4. C. Comninellis and G.H. Chen, Electrochemistry for the Environment. Springer Science Business Media, New York (2010).

5. C. Comninellis, A. Kapalka, S. Malato, S.A. Parsons, I. Poulios and D. Mantzavinos, J. Chem. Technol. Biotechnol., 83, 769 (2008).

6. R.T. Pelegrini, R.S. Freire, N. Duran and R. Bertazzoli, Environ. Sci. Technol., 35, 2849 (2001).

7. J. Peller, O. Wiest and P.V. Kamat, Environ. Sci. Technol., 37, 1926 (2003).

8. K. Vinodgopal, S. Hotchandani and P.V. Kamat, J. Phys. Chem., 97, 9040 (1993).

9. Z.C. Wu and M.H. Zhou, Environ. Sci. Technol., 35, 2698 (2001).

10. L.B. Stadler, A.S. Ernstoff, D.S. Aga and N.G. Love, Environ. Sci. Technol., 46, 10485 (2012).

11. A.M. Polcaro, S. Palmas, F. Renoldi and M. Mascia, J. Appl. Electrochem., 29, 147 (1999).

12. G.T. Li, J.H. Qu, X.W. Zhang and J.T. Ge, Water Res., 40, 213 (2006).

13. C. Hu, X.X. Hu, J. Guo and J.H. Qu, Environ. Sci. Technol., 40, 5508 (2006).

14. T. A. M. Haemers, D.J. W. Ijdo, Mater. Res. Bull., 26, 989 (1991).

15. J.R. Feng and D.C. Johnson, J. Electrochem. Soc., 138, 3328 (1991).

16. G.T. Li, H.Y. Yip, Ch. Hu and P.K. Wong, Mater. Res. Bull., 46, 153 (2011).

17. X.Z. Li, H.L. Liu, P.T. Yue and Y.P. Sun, Environ. Sci. Technol., 34, 4401 (2000).

18. S.P. Yu, Research of Photoelectric Catalytic Degradation of Organic Dyes, Doctor Dissertation of South China University of Technology (2004) (in Chinese). 